\title{
Strategies for colon cancer prevention
}

\author{
Jan Björk
}

Received: 30 April 2010 /Accepted: 5 August 2010/Published online: 12 September 2010

(C) European Association for Predictive, Preventive and Personalised Medicine 2010

\begin{abstract}
Colorectal cancer (CRC) is common and is associated with a considerable mortality. Morbidity and thereby mortality can be reduced by using different prevention strategies such as lifestyle interventions and chemoprevention. Endoscopic surveillance of high-risk individuals and population-based endoscopic screening of average-risk individuals enables detection and removal of premalignant lesions (adenomas) as well as presymptomatic detection of cancer. Implementation of cancer detection tests such as fecal occult blood tests (FOBTs) is another strategy to reduce cancer mortality by early detection of CRC. Personalized management, based on estimates of the individual risk using information concerning environmental factors, lifestyle, family history, personality, social background and phenotype in combination with a variety of biomarkers such as genotype, will become more important as a strategy to optimize CRC prevention in the future.
\end{abstract}

Keywords Colorectal cancer · Prevention · Screening · Surveillance

\section{Introduction}

Colorectal cancer (CRC) is one of the most prevalent malignancies in Western countries with a life-time risk of 5\% to $6 \%$ [1]. Global statistics shows that European countries have a leading position, both in terms of incidence and

\section{J. Björk ( ()}

Department of Gastroenterology and Hepatology,

Karolinska University Hospital,

Stockholm, Sweden

e-mail: jan.bjork@karolinska.se mortality of CRC. It has been estimated that approximately $50 \%$ die of the disease. The incidence and mortality in CRC varies over countries even within Europe indicating an influence of other factors such as lifestyle and screening practices [2]. CRC could be divided into at least three types: sporadic, hereditary and colitis-associated. A large body of evidence indicates that diet and lifestyle, family history and chronic inflammation are risk factors for CRC. Thus, primary prevention by modification of environmental factors and lifestyle, identification, surveillance and prophylactic treatment of high-risk individuals and the use of chemoprevention are important. However, the most efficient way to prevent CRC or death from CRC among the general population is screening targeting the average risk individuals. Therefore populationbased screening programs, including all people eligible to attend screening on the basis of age and geographical area of residence, are currently being implemented in several European countries and more will follow. In the United States there is a trend towards a decrease in CRC morbidity and mortality. Microsimulation modeling demonstrates that declines in CRC death rates are explained to a small but demonstrable extent by risk factor reductions and improved treatments and to a great extent by screening [3]. The aim of population-based screening is to discover latent disease in the average risk population in order to detect early stages which can be cured by treatment before it poses a threat to the individual and/or the community [4]. CRC is particularly suitable for screening since it is common and believed to develop gradually according to the adenoma-carcinoma sequence [5]. The time-span from an early adenoma to an established CRC is unobserved, but is estimated to take at least 10 years [6], thus providing an opportunity for early detection and intervention. Moreover, removal of colorectal adenomas has a preventive effect on CRC [7] and detection of CRC at an earlier stage 
affects mortality [8] which indicates that interventions along the adenoma-carcinoma pathway have a positive impact on outcome. Identification and surveillance of high-risk populations such as individuals belonging to families with hereditary CRC syndromes and patients with inflammatory bowel disease (IBD) are other measures of great importance. Individuals with a family history of CRC indicating a genetic predisposition but without detectable genetic markers or individuals with a phenotypic appearance indicating high-risk is a third group where surveillance is justified. There are several screening options for CRC available where fecal occult blood tests (FOBTs) and lower endoscopy are the most commonly used.

\section{Primary prevention}

Primary prevention strategies are targeted to prevent CRC in an otherwise healthy population. The decline in CRC seen in the United States is prognosticated to continue if risk factor modification remains at current rates. With favorable trends in risk factor exposure decrease could probably be even more pronounced. Many cancers have modifiable risk factors, although risk factor reduction usually results in long-term, not short-term, improvements in cancer incidence. Thus, the impact of changing prevalence of CRC risk factors must be assessed over a long time to observe impact [9].

Physical inactivity

Lifestyle such as lack of physical exercise is a risk factor for CRC [10] and decreased occupational physical activity increases the risk for colon cancer [11].

\section{Obesity}

There is considerable evidence supporting the concept that both overweight and obesity are associated with an increased risk of CRC. Obesity also increases the risk of colon adenomas [12]. Overall, obesity approximately doubles the relative risk of adenomas. A meta-analysis of six studies estimated a $3 \%$ increase in CRC risk per one unit increase in body mass index (BMI). Abdominal obesity is a stronger risk factor than truncal obesity or BMI [13, 14].

\section{Smoking}

Smoking is a strong predictor of CRC $[15,16]$. A history of more than 20 pack-years of smoking increases the risk for colorectal adenomas and CRC $[17,18]$ and has been shown to account for $12 \%$ of all deaths from $\operatorname{CRC}[19,20]$. Based on these data, special efforts may be justified to ensure that screening takes place in active smokers and in former who have smoked for more than 20 pack-years.

Diet

The geographic differences in CRC incidence could, at least to some extent, be attributed to differences in diet habits. The association of high incidence of CRC with diets containing large amount of red meat emphasises the impact of diet [21]. The WCRF [22] recognizes that there is limited but suggestive evidence that food containing animal fat increases the risk of CRC. But there is also data suggestive of a causal relationship between high intake of n-3 longchain polyunsaturated fatty acids (LC-PUFA) and reduced risk of $\mathrm{CRC}$, indicating that fish intake probably have a CRC protective effect [23]. A systematic review of five studies failed to show any benefit of increased dietary fiber intake for reducing incidence or recurrence of adenomatous polyps [24]. The role of nutritional supplementation is difficult to assess. Nutritional chemoprevention trials had to be carried out with large number of patients studied for long duration, measuring $\mathrm{CRC}$ as an end point. Folic acid has been identified as possible agents for the chemoprevention of CRC. However, a recent meta-analysis showed no such evidence [25]. Pooled data from 60 epidemiological studies on CRC cases showed that higher consumption of milk/dairy products reduces the risk of colon cancer, and high calcium intake reduces the risk of CRC. Evidence from two randomized controlled trials suggests that calcium supplementation contribute to a moderate degree to the prevention of colorectal adenomas. Vitamin D was associated with a non significant reduction in CRC risk [26]. The Polyp Prevention Study was a clinical trial of antioxidant vitamins (ß-carotene, vitamins $\mathrm{C}$ and $\mathrm{E}$ ). No effect was seen on recurrence of colorectal adenomas compared to placebo [27]. A high-quality meta-analysis of eight trials found that, compared with no treatment or placebo, there was no benefit of antioxidants (beta-carotene, vitamin $\mathrm{A}$, vitamin $\mathrm{C}$, vitamin $\mathrm{E}$, or selenium) in decreasing the risk of CRC. Vitamin $\mathrm{E}$ was, in fact, found to increase the risk of colorectal adenomas [28].

\section{Chemoprevention}

Nonsteroidal anti-inflammatory drugs (NSAIDs)

NSAIDs including selective cyclooxygenase-2 inhibitors (COXIBs) have a chemopreventive effect on CRC [29]. Elevated cyclooxygenase-2 (COX-2) expression is found in most CRC tissue and is associated with poor outcome in terms of survival among CRC patients. NSAIDs exert their anti-inflammatory and antitumor effects primarily by 
reducing prostaglandin production by inhibition of COX-2 activity [30]. It has been possible to reduce the formation of colorectal adenomas of both familial and sporadic origin by treating with NSAIDs [29, 31]. COXIBs have also been shown to cause regression of polyps in randomized studies on patients with familial adenomatous polyposis (FAP) [32, 33]. Evidence of long-term efficacy of NSAIDs is, however, currently lacking and potential severe adverse events must be taken into account [29]. Moreover, the use of NSAIDs in FAP patients does not replace prophylactic colorectal surgery. Currently, the use of NSAIDs is restricted as adjunctive treatment in FAP patients with ileorectal anastomosis in order to reduce polyp burden. However, endoscopic surveillance of the rectum is still advocated [34].

Aminosalicylic acid (ASA)

ASA has in observational studies been associated with significant reductions in colorectal adenoma recurrence, CRC incidence, and CRC mortality $[35,36]$.

\section{5-Aminosalicylate (5-ASA)}

Pooled results of observational studies support a protective association between 5-ASA and CRC or a combined endpoint of $\mathrm{CRC} /$ dysplasia in patients with ulcerative colitis (UC) [37-39].

\section{Ursodeoxycholic acid (UDCA)}

UCDA was one of the earliest agents investigated as a drug for $\mathrm{CRC}$ prevention. In a randomized controlled trial in patients with colorectal adenomas UDCA significantly lowered the odds of advanced lesions in men, but not women [40]. UDCA also has been shown to reduce the risk of colorectal dysplasia or CRC in patients with primary sclerosing cholangitis (PSC) and UC [41, 42].

\section{Statins}

A population-based case-control study found that CRC was $30 \%$ less likely to occur in patients who took statins for at least 5 years but data from randomized controlled trials are lacking [43].

\section{Hormon therapy}

Two meta-analyses of mostly observational cohort studies reported a $20-30 \%$ reduction in colon cancer incidence in women who had ever used hormone therapy [44, 45]. However, data from the Women's Health Initiative study showed that, although women were at decreased risk of developing colon cancer, those women who did develop colon cancer were diagnosed at a more advanced stage than women who took placebo [46].

\section{Family history}

Inherited susceptibility plays an important role in the pathogenesis of CRC. Thus, it is recommended that a careful family history always should be obtained. Where a positive history is presented the empirical risks for the development of CRC can be determined. When no hereditary CRC syndrome is evident, screening is based on empiric risk estimates. For instance, the CRC risk is increased twofold [47] and the odds ratio is 2.6 for highrisk adenomas defined as adenomas $\geq 1 \mathrm{~cm}$ in size and/or villous elements in individuals with only one affected firstdegree relative with $\mathrm{CRC}$ which further emphasize the close relationship between adenomas and CRC and the importance of the adenoma-carcinoma sequence [48]. The American College of Gastroenterology (ACG) recommendations are colonoscopy every 10 years beginning at age 50 years when following criteria are fulfilled: a single first-degree relative with CRC or high-risk adenoma, defined as adenoma $\geq 1 \mathrm{~cm}$ in size, or with high-grade dysplasia or villous elements, diagnosed at age $\geq 60$ years (Grade 2 B). The recommendations are colonoscopy every 5 years beginning at age 40, or 10 years younger than age at diagnosis of the youngest affected relative if the following criteria are fulfilled: single first-degree relative with $\mathrm{CRC}$ or advanced adenoma diagnosed at age $<60$ years or two first-degree relatives with CRC or high-risk adenomas (Grade 2 B) [49].

If phenotype and/or inheritance pattern indicate an inherited CRC syndrome, genetic counseling, presymtomatic endoscopic screening and, if appropriate, molecular genetic testing should be advised. It is possible to test selected subjects for carriage of germline mutations in genes responsible for Lynch syndrome/hereditary nonpolyposis colorectal cancer (HNPCC), familial adenomatous polyposis (FAP), Peutz-Jeghers syndrome, and juvenile polyposis which are all autosomal dominant hereditary syndromes with CRC predisposition. Molecular genetic testing is also possible for MUTYH- associated polyposis (MAP), a syndrome resembling FAP but, unlike FAP, inhereted in an autosomal recessive fashion. Once the mutation has been found selected members of the family (at risk individuals), who are identified from the pedigree, can be offered genetic testing.

Before genetic testing is performed in patients who meet the criteria for Lynch syndrome microsatellite instability testing and / or tumor immunohistochemical staining for mismatch repair proteins should be performed. Patients with positive tests can be offered genetic testing and, if the mutation is found, all family members at risk can be offered 
genetic testing. ACG recommends that patients with positive genetic testing and those at risk in families where genetic testing is unsuccessful should be offered colonoscopy every 1 year to 2 years beginning at age 20-25 years, until age 40 years, then annually thereafter (Grade 2 B) [49].

The European guidelines recommend that individuals with a FAP- phenotype should undergo APC-mutation testing and, if negative, MUTYH-mutation testing. Patients with FAP or at risk of FAP should undergo annual flexible sigmoidoscopy or colonoscopy until preventive surgery is performed [50]. Despite surgical procedure used postsurgical endoscopic surveillance is mandatory. Patients with ileorectal anastomosis, ileal pouch, or an ileostomy, should undergo endoscopic surveillance approximately every 6-12 months according to the ACG recommendations (Grade $2 \mathrm{~B}$ ). Individuals with less dense polyp burden $(<100$ colorectal polyps) should be offered genetic counseling, consideration of APC- and MUTYH- mutation testing, and individualized colonoscopy surveillance depending on the size, number, and pathology of polyps seen according to the same recommendations (Grade 2 C) [49]. Despite of phenotype it is not always possible to find the mutation causing the syndrome. In these families endoscopic surveillance of at risk individuals is recommended. Screening strategies targeting risk populations based on family history of CRC have been estimated to prevent up to 15$20 \%$ of all CRC [51].

\section{Inflammatory bowel disease (IBD)}

It was shown decades ago that longstanding extensive ulcerative colitis (UC) was associated with an increased risk of CRC [52, 53]. UC-associated CRC are more often multiple, broadly infiltrating, anaplastic, and uniformly distributed throughout the colon, and seem to arise from flat mucosa and not from adenomas in comparison with noncolitis-associated CRC [54]. After 10 years of extensive UC, the cancer risk has been reported to increase with $0.5-$ $1 \%$ per year [55]. Even patients with left-sided UC reach similar levels of cumulative cancer risk but first after 30 40 years of disease [56]. Regular surveillance colonoscopy has been proposed after $8-10$ years of colitis with multiple biopsies at regular intervals. The finding of high grade dysplasia (HGD) in flat mucosa is an indication for prophylactic colectomy or proctocolectomy. Patients especially at risk for CRC are those with primary sclerosing cholangitis (PSC) [57]. It is therefore justified to start colonoscopic surveillance as soon as the coexisting diagnoses of UC and PSC are established and offer this patients treatment with UCDA [42]. In addition, a family history of CRC is also an independent risk factor [58]. Only indirect evidence indicate that surveillance colono- scopy is likely to be effective at reducing the risk of death from UC-associated carcinoma, particularly in those with long-standing extensive colitis [59]. Pharmacological intervention with 5-ASA has been shown to reduce the risk of CRC and dysplasia up to 50\% [37]. Previous epidemiological studies imply that an increased risk of CRC is valid for Crohn's disease as well $[59,60]$.

\section{Screening}

Population based CRC screening has been introduced in several countries throughout the world. The age range for a screening program should include a cohort of the population fulfilling the criteria of both high incidence of CRC and still a considerable life-expectancy. Colonoscopic detection of CRC is uncommon in asymptomatic individuals below 50 years of age. The low yield of screening colonoscopy in younger adults is consistent with current recommendations, not starting screening before age 50 in individuals at average risk [61]. CRC screening tests could be divided into cancer prevention and cancer detection tests. Cancer prevention tests have the potential to detect both cancer and adenomas, whereas cancer detection tests have low sensitivity for adenomas but also lower sensitivity for cancer compared with that in cancer prevention tests (imaging tests).

\section{Imaging tests}

Endoscopic screening examination could be performed either as a flexible sigmoidoscopy or as a colonoscopy. In CRC screening of average-risk individuals both methods are used. Sigmoidoscopy is easier to perform and less time consuming and is associated with less complications compared to colonoscopy [62]. Case-control studies of sigmoidoscopy, have shown morbidity and mortality reductions of distal CRC of 80 [63] and 60\% [64], respectively, in screening populations. Overall, flexible sigmoidoscopy detects $60-70 \%$ of the significant lesions detected by colonoscopy [65]. The Telemark Polyp Study conducted in Norway was a randomized controlled trial where flexible sigmoidoscopy was used demonstrated a significant reduction in the incidence of CRC [66]. A similar study from the United Kingdom presented data on the attendance rate which was only $45 \%$ [31]. The evidence that colonoscopy prevents incident CRCs and reduces the mortality from CRC is indirect but substantial. Notably, no prospective randomized controlled trial, comparing colonoscopy with no screening, has been carried out. However, cohort studies containing patients, who have undergone colonoscopy and polypectomy have shown a 76-90\% reduction in CRC morbidity compared to reference pop- 
ulations [7, 67]. Case-control studies of colonoscopy have shown an $80 \%$ reduction in the CRC morbidity [68] and a $50 \%$ reduction in mortality from CRC [69]. Populationbased studies associated increased use of colonoscopy with earlier and more favorable stages in CRC presentation, and with reductions in the incidence of CRC $[70,71]$. In a very recent study no CRCs were detected at colonoscopy in participants who had a negative colonoscopy an average of 11.9 years previously, compared with the 8.4 CRC cases expected based on age- and gender-specific prevalences among participants who had not received a colonoscopy. The low risk of CRC after a negative colonoscopy support that screening intervals can be extended to at least 10 years after a negative index colonoscopy [72]. Major advantages of colonoscopy are that it allows examination of the entire colon, as well as single-session diagnosis and treatment. Disadvantages are the requirement for thorough bowel preparation and the perforation risk [73, 74]. Most perforations are related to polypectomy. However, use of effective polypectomy techniques is critical for adequate resection of larger polyps. Two studies, addressing this issue, come to the conclusion that about $25 \%$ of incident cancers occurring after colonoscopy result from ineffective polypectomy $[75,76]$. Several studies have shown that the detection rates of adenomas differs a lot between different colonoscopists, including high-risk adenomas [77-79]. Thus, the impact of colonoscopy depends critically on high-quality baseline examinations. Inadequate bowel preparation is common, and inadequate preparation has been shown to impair the detection of polyps [80, 81], and has also been shown recently in prospective colonoscopy studies to correlate with polyp detection [82-84]. CT colonography is a viable alternative in patients who decline colonoscopy. The rational is that the sensitivity for polyps $\geq 1 \mathrm{~cm}$ in size in the most recent multicenter trial was $90 \%$ [85]. The CT colonography probably has a lower risk of perforation than colonoscopy in most settings, but for several reasons it is not considered the equivalent of colonoscopy as a screening strategy. First, the evidence to support an effect of endoscopic screening on prevention of incident CRC and mortality is overwhelming compared with that for CT colonography. Second, the inability to detect polyps $\leq 5 \mathrm{~mm}$, which constitutes $80 \%$ of colorectal neoplasms, and whose natural history is still not understood, necessitates performance of the test at 5-year, rather than 10-year intervals [86].

\section{Fecal bleeding tests}

Guaiac-based fecal occult bleeding test (gFOBT) has so far been the most frequently used test in screening programs. It detects the peroxidase reaction of hemoglobin, which causes the detection paper impregnated with guaiac resin to turn blue. Diet restrictions are necessary to avoid falls positive results. There is good evidence that gFOBT reduces mortality of CRC by $15-33 \%$ [87]. There is still no clear recommendation regarding optimal time interval since only the interval up to 2 years has been investigated. The immunochemical FOBT (iFOBT) is more expensive than the gFOBT but the adherence is better [88, 89]. iFOBT reacts exclusively to human hemoglobin. Several qualitative and quantitative tests are presently available, with varying levels of sensitivity and specificity.

New screening methods include tests which examine the stool for the presence of abnormal DNA are commercially available. Generally, these tests have higher sensitivity but lower specificity than gFOBT [90]. Fecal DNA testing is also more expensive. Additional disadvantages of fecal DNA testing include no established data on which to determine an optimal interval, and the lack of clinical recommendations on how to respond to patients who have positive DNA tests and negative colonoscopies. Introduction of organized, population-based, colorectal cancer screening using FOBT has the potential to reduce overall CRC cancer mortality. However, a recent study from the United Kingdom shows that socio-economic variation in screening participation could exacerbate existing inequalities in mortality. The results showed a strong socioeconomic gradient in FOBT uptake, which declined from $49 \%$ in the least deprived quintile of postcodes to $38 \%$ in the middle quintile and $32 \%$ in the most deprived quintile. Variation in socio-economic deprivation between sectors accounted for $62 \%$ of the variance in return rates, with little attenuation as a result of controlling for ethnic diversity, household mobility or health status. These results highlight the need to understand the causes of socio-economic gradients in screening participation and address barriers that could otherwise influence outcome in CRC survival [91]. ACG recommends a preferred cancer prevention test with colonoscopy every 10 years (Grade $1 \mathrm{~B}$ ) starting at age 50 years in those without a family history of colorectal neoplasia and a preferred cancer detection test using annual iFOBT to detect occult bleeding (Grade $1 \mathrm{~B}$ ). In clinical settings, in which economic issues preclude primary screening with colonoscopy, or for patients who decline colonoscopy, one of either flexible sigmoidoscopy every 5-10 years or CT colonography every 5 years should be offered. As cancer detection test, occult blood detection through the iFOBT is recommended [49].

\section{Surveillance}

Colonoscopy is used for early detection and prevention of $\mathrm{CRC}$ by identification of $\mathrm{CRC}$ and removal of colorectal polyps. An autopsy survey and a prospective necropsy study of the colon and rectum showed that adenomas were 
very common lesions occurring in approximately $50 \%$ and $30 \%$ of the patients, respectively $[92,93]$. Approximately $70 \%$ of colonoscopically removed polyps are adenomas [94]. Adenomas are benign lesions that, by definition, display dysplasia. It is postulated that almost all CRCs arise from adenomas but only a small fraction of them undergo malignant transformation. It is estimated that the development from normal mucosa via adenoma to CRC takes several years [5]. The purpose of surveillance endoscopy is to detect and resect synchronous adenomas missed during the initial colonoscopy and to remove metachronous lesions before they get malignant. Several studies have been performed investigating the recurrence rate of adenomas in patient with adenomas at previous colonoscopy. The risk of metachronous adenomas is high, between $42 \%$ and $60 \%$ after 3 years and 4 years, respectively according to two previous studies $[95,96]$. The majority of these lesions are small and probably of low clinical significance. The National Polyp Study (NPS) has shown that only 3.3\% of the patients with colorectal adenomas had advanced lesions including 2 early CRCs 3 years after the index colonoscopy. Based on this an endoscopic surveillance interval of at least 3 years was recommended [97]. The miss rate of synchronous polyps at colonoscopy is not neglectable [98]. It is however clear that that some individuals are predisposed to a faster rate of polyp development. Predictors of adenoma recurrence are number and size of adenomas. Patients with up to 2 adenomas measuring less than $1 \mathrm{~cm}$ at initial colonoscopy have a low risk of developing adenomas of clinical importance within 3 years whereas patients with 3 or more adenomas with at least one measuring $1 \mathrm{~cm}$ or more is a high-risk population which is recommended follow-up colonoscopy at 3 years [99]. Predictors of colorectal cancer are, except for number and size, the histological features of tubulovillous or villous growth [100]. Colonoscopic removal of at least 1 adenoma larger than $5 \mathrm{~mm}$ reduced the risk of subsequent CRC development compared with that expected in the general population indicating that endoscopic intervention is efficient in reducing morbidity in CRC in patients under regular colonoscopic surveillance [101]. Moreover, prevalence of left-sided advanced colorectal lesions, but not right-sided advanced lesions, has been shown to be reduced within a 10 -year period after colonoscopy, even in the community setting [102]. Resources in terms of money and accessibility as well as compliance rate have to be taken into account when designing the endoscopic surveillance setting.

\section{Outlook}

CRC morbidity and mortality can be reduced. A concerted action including lifestyle changes, chemoprevention, sur- veillance of high-risk individuals, and population-based screening of average-risk individuals is at present the most efficient strategy. Factors that have to be taken into account are compliance, sensitivity, specificity, cost, and safety. Insufficient adherence to lifestyle recommendations and low attendance to screening programs are important factors that affect the outcome of CRC prevention in the general population and must by all means be improved. As predictive diagnostics, such as genetic testing using advanced molecular technologies, develop and become more widely used the population of well defined and more motivated high-risk individuals will increase in size compared with today. Once a high-risk individual has been identified targeted preventive measures and treatment can be implemented. In the future, personalized surveillance and treatment based on the risk profile involving the genetic background, a variety of biomarkers, phenotype, lifestyle, personality and social background probably will become more important as a strategy to optimize CRC prevention.

\section{References}

1. Jermal A, Siegel R, Ward E, Hao Y, Xu J, Murray T, et al. Cancer statistics 2008. CA Cancer J Clin. 2008;58:71-96.

2. Ferlay J, Autier P, Boniol M, Heanue M, Colombet M, Boyle P. Estimates of the cancer incidence and mortality in Europe in 2006. Ann Oncol. 2007;18:581-92.

3. Edwards BK, Ward E, Kohler BA, Eheman C, Zauber AG, Anderson RN, et al. Annual report to the nation on the status of cancer, 1975-2006, featuring colorectal cancer trends and impact of interventions (risk factors, screening, and treatment) to reduce future rates. Cancer 2009 Dec 7. [Epub ahead of print].

4. Wilson JM, Jungner YG. Principes and practice of mass screening for disease. Bol Oficina Sanit Panam. 1968;65:281-93.

5. Morson BC. The evolution of colorectal carcinoma. Clin Radiol. 1984;35:425-31.

6. Winawer SJ, Fletcher RH, Miller L, Godlee F, Stoler MH, Mulrow CD, et al. Colorectal cancer screening: clinical guidelines and rational. Gastroenreiology. 1997;112:594-642.

7. Winawer SJ, Zauber AG, Ho MN, O'Brien MJ, Gottlieb LS, Sternberg SS, et al. Prevention of colorectal cancer by colonoscopic polypectomy. N Engl J Med. 1993;329:1977-81.

8. Ciccolalla L, Capocaccia R, Coleman MP, Berrino F, Coebergh JW, Damhuis RA, et al. Survival differences European and US patients with colorectal cancer: role of stage at diagnosis and surgery. Gut. 2005;54:268-73.

9. Cronin KA, Krebs-Smith SM, Feuer EJ, Troiano RP, BallardBarbash R. Evaluating the impact of population changes in diet, physical activity, and weight status on population risk for colon cancer (United States). Cancer Causes Control. 2001;12:305-16.

10. Juarranz M, Calle-Puron ME, Gonzales-Navarro A, RegidorPoyatos E, Soriano T, Martinez Hernandez D, et al. Physical exercise, use of Plantago ovata and aspirin, and reduced risk of colon cancer. Eur J Cancer Prev. 2002;11:465-72.

11. Moradi T, Gridley G, Björk J, Dosemeci M, Ji BT, Berkel HJ, et al. Occupational physical activity and risk for cancer of the colon and rectum in Sweden among men and women by anatomic subsite. Eur J Cancer Prev. 2008;17(3):201-8. 
12. Bird CL, Frankl HD, Lee ER, et al. Obesity, weight gain, large weight changes, and adenomatous polyps of the left colon and rectum. Am J Epidemiol. 1998;147:670-80.

13. Bergstrom A, Pisani P, Tenet V, et al. Overweight as an avoidable cause of cancer in Europe. Int J Cancer. 2001;91:421-30.

14. Giovannucci E. Insulin, insulin-like growth factors and colon cancer: a review of the evidence. J Nutr. 2001;131:3109-20.

15. Driver JA, Gaziano JM, Gelber RP, et al. Development of a risk score for colorectal cancer in men. Am J Med. 2007;120:25763.

16. Gondal G, Grotmol T, Hofstad B, Bretthauer M, Eide TJ, Hoff G. Lifestyle-related risk factors and chemoprevention for colorectal neoplasia: experience from the large-scale NORCCAP screening trial. Eur J Cancer Prev. 2005;14:373-9.

17. Giovannucci E. An updated review of the epidemiological evidence that cigarette smoking increases risk of colorectal cancer. Cancer Epidemiol Biomarkers Prev. 2001;10:725-31.

18. Terry P, Ekbom A, Lichtenstein P, et al. Long-term tobacco smoking and colorectal cancer in a prospective cohort study. Int $\mathrm{J}$ Cancer. 2001;91:585-7.

19. Caho A, Thun MJ, Jacobs EJ, et al. Cigarette smoking and colorectal cancer mortality in the cancer prevention study II. J Natl Cancer Inst. 2000;92:1888-96.

20. Caongelo LA, Gapstur MS, Gann PH, et al. Cigarette smoking and colorectal carcinoma mortality in a cohort with long-term follow-up. Cancer. 2004;100:288-93.

21. Giovannucci E, Willett WC. Dietary factors and risk of colon cancer. Ann Med. 1994;26:443-52.

22. WCFR/AICR: Food Nutrition, Physical Activity and the Prevention of Cancer: A Global Perspective. Washington, American Institute for Cancer Research, 2007.

23. Gerber M. Background review paper on total fat, fatty acid intake and cancers. Ann Nutr Metab. 2009;55:140-61.

24. Asano TK, McLeod RS. Dietary fibre for the prevention of colorectal adenomas and carcinomas. Cochrane Database Syst Rev 2008;(3):CD003430.

25. Carroll C, Cooper K, Papaioannou D, Hind D, Tappenden P, Pilgrim $\mathrm{H}$, et al. Meta-analysis: folic acid in the prevention of colorectal adenomas and the chemoprevention of colorectal cancer. Aliment Pharmacol Ther 2010 Jan 18. [Epub ahead of print].

26. Huncharek M, Muscat J, Kupelnick B. Colorectal cancer risk and dietary intake of calcium, vitamin $\mathrm{D}$, and dairy products: a metaanalysis of 26, 335 cases from 60 observational studies. Nutr Cancer. 2009;61(1):47-69.

27. Greenberg R, Baron J, Toseson T, Freeman D, Beck GJ, Bond J, et al. A clinical trail of antioxidant vitamins to prevent colorectal adenoma. N Engl J Med. 1994;331:141-7.

28. Bjelakovic G, Nagorni A, Nikolova D, Simonetti RG, Bjelakovic M, Gluud C. Meta-analysis: antioxidant supplements for primary and secondary prevention of colorectal adenoma. Aliment Pharmacol Ther. 2006;24(2):281-91.

29. Rostom A, Dube C, Lewin G, Tsertvadze A, Barrowman N, Code $\mathrm{C}$, et al. Nonsteroidal anti-inflammatory drugs and cyclooxygenase2 inhibitors for primary prevention of colorectal cancer: a systematic review prepared for the U.S. Preventive Services Task Force. Ann Intern Med. 2007;146:376-89.

30. Wang D, Dubois RN. The role of COX-2 in intestinal inflammation and colorectal cancer. Oncogene. 2009 Nov 30. [Epub ahead of print].

31. Giardiello FM, Hamilton SR, Krush AJ, Piantadosi S, Hylind LM, Celano P, et al. Treatment of colonic and rectal adenomas with sulindac in familial adenomatous polyposis. $\mathrm{N}$ Engl $\mathrm{J}$ Med. 1993;328:1313-6.

32. Steinbach G, Lynch PM, Phillips RK, Wallace MH, Hawk E, Gordon GB. The effect of celecoxib, a cyclooxygenase-2 inhibitor, in familial adenomatous polyposis. N Engl J Med. 2000;342:1946-52.
33. Higuchi T, Iwama T, Yoshinaga K, Toyooka M, Taketo MM, Sugihara K. A randomized, double-blind, placebo-controlled trial on the effect of rofecoxib, a selective cyclooxygenase-2 inhibitor, on rectal polyps in familial adenomatous polyposis patients. Clin Cancer Res. 2003;9:4756-60.

34. Jalving M, Koornstra JJ, De Jong S, De Vries EGE, Kleibeuker JH. Review article: the potential of combination regimen with non-steroidal anti-inflammatory drugs in the chemoprevention of colorectal cancer. Aliment Pharmacol Ther. 2005;21:321-39.

35. Giovannucci E, Rimm EB, Stampfer MJ, Colditz GA, Ascherio A, Willet AC. Aspirin use and the risk for colorectal cancer and adenoma in male health professionals. Ann Intern Med. 1994;121:241-6.

36. Thun MJ, Namboodiri MM, Heath Jr CW. Aspirin use and reduced risk of fatal colon cancer. N Engl J Med. 1991;325:1593-6.

37. Velayos FS, Terdiman JP, Walsh JM. Effect of 5-aminosalicylate use on colorectal cancer and dysplasia risk: a systematic review and metaanalysis of observational studies. Am J Gastroenterol. 2005;100:1345-53.

38. Sandborn WJ. Treatment of ulcerative colitis with oral mesalamine: advance in drug formulation, efficacy expectations and dose response, compliance, and chemoprevention. Rev Gastroenterol Disord. 2006;6:97-105.

39. Munkholm P, Loftus EV, Reinacher-Schick A, Kornbluth A, Mittmann U, Esendal B. Prevention of colorectal cancer in inflammatory bowel disease: value of screening and 5aminosalicylates. Digestion. 2006;73:11-9.

40. Thompson PA, Wertheim BC, Roe DJ, Ashbeck EL, Jacobs ET, Lance P, et al. Gender modifies the effect of ursodeoxycholic acid. Cancer Prev Res (Phila Pa). 2009;2(12):1023-30.

41. Tung BY, Emond MJ, Haggit RC, Bronner MP, Kimmey MB, Kowdley KV, et al. Ursodiol use is associated with lower prevalence of colonic neoplasia in patients with ulcerative colitis and primary sclerosing cholangitis. Ann Intern Med. 2001;134:89-95.

42. Pardi DS, Loftus EV, Kremers WR, Keach J, Lindor KD. Ursodeoxycholic acid as a chemopreventive agent in patients with ulcerative colitis and primary sclerosing cholangitis. Gastroenterology. 2003;124:889-93.

43. Poynter JN, Gruber SB, Higgins PD, et al. Statins and the risk of colorectal cancer. N Engl J Med. 2005;352(21):2184-92.

44. Grodstein F, Newcomb PA, Stampfer MJ. Postmenopausal hormone therapy and the risk of colorectal cancer: a review and meta-analysis. Am J Med. 1999;106(5):574-82.

45. Nanda K, Bastian LA, Hasselblad V, Simel DL. Hormone replacement therapy and the risk of colorectal cancer: a metaanalysis. Obstet Gynecol. 1999;93(5 Pt 2):880-8.

46. Chlebowski RT, Wactawski-Wende J, Ritenbaugh C, for the Women's Health Initiative Investigators, et al. Estrogen plus progestin and colorectal cancer in postmenopausal women. $\mathrm{N}$ Engl J Med. 2004;350(10):991-1004.

47. Fuchs CS, Giovannucci EL, Colditz GA, Hunter DJ, Speizer FE, Willett WC. A prospecyive study of family history and the risk of colorectal cancer. N Engl J Med. 1994;331:1669-74.

48. Pariente A, Milan C, Lafon J, Faivre J. Colonoscopic screening in first-degree relatives of patients with 'sporadic' colorectal cancer: a case-control study. Gastroenterology. 1998;115:7-12.

49. Rex DK, Johnson DA, Anderson JC, Schoenfeld PS, Burke CA, Inadomi JM. American College of Gastroenterology Guidelines for Colorectal Cancer Screening 2008. Am J Gastroenterol. 2009;104:739-50.

50. Vasen HF, Moslein G, Alonso A, et al. Guidelines for the clinical management of familial adenomatous polyposis (FAP). Gut. 2008;57:704-13.

51. Boutron MC, Faivre J, Quipourt V, Senesse P, Michiels C. Family history of colorectal tumours and implications of the 
adenoma-carcinoma sequence: a case-control study. Gut. 1995;37:830-4.

52. Greenstein AJ, Sachar DB, Smith H, et al. Cancer in universal and left-sided ulcerative colitis: factors determining risk. Gastroenterology. 1979;77:290-4.

53. Jensen AB, Larsen M, Gislum M, Skriver MV, Jepsen P, Norgaard B, et al. Survival after colorectal cancer in patients with ulcerative colitis: a nationwide population-based Danish study. Am J Gastroenterol. 2006;101:1283-7.

54. Sugita A, Sachar DB, Bodian C, et al. Colorectal cancer in ulcerative colitis. Influence of anatomical extent and age at onset on colitis - cancer interval. Gut. 1991;32:167-9.

55. Eaden JA, Abrams KR, Mayberry JF. The risk of colorectal cancer in ulcerative colitis: a meta-analysis. Gut. 2001;48:526-35.

56. Sugita A, Sachar DB, Bodian C, et al. Colorectal cancer in ulcerative colitis. Influence of anatomical extent and age at onset on colitis - cancer interval. Gut. 1991;32:167-9.

57. Broome U, Lofberg R, Veress B, et al. Primary sclerosing cholangitis and ulcerative colitis: evidence for increased neoplastic potential. Hepatology. 1995;22:1404-8.

58. Askling J, Dickman PW, Karlen P, et al. Family history as a risk factor for colorectal cancer in inflammatory bowel disease. Gastroenterology. 2001;120:1356-62.

59. Jess T, Gamborg M, Matzen P, Munkholm P, Sørensen TI. Increased risk of intestinal cancer in Crohn's disease: a metaanalysis of population-based cohort studies. Am J Gastroenterol. 2005;100(12):2724-9.

60. Ekbom A, Helmick C, Zack M, Adami HO. Increased risk of large-bowel cancer in Crohn's disease with colonic involvement. Lancet. 1990;336(8711):357-9.

61. Imperiale TF, Wagner DR, Lin CY, Larkin GN, Rogge JD, Ransohoff DF. Results of screening colonoscopy among persons 40 to 49 years of age. N Engl J Med. 2002;346(23):1781-5.

62. Segnan N, Senore C, Andreoni B, Arrigoni A, Bisanti L, Cardelli A, et al. Randomized trial of different screening strategies for colorectal cancer: patient response and detection rates. J Natl Cancer Inst. 2005;97(5):347-57.

63. Newcomb PA, Storer BE, Morimoto LM, et al. Long-term efficacy of sigmoidoscopy in the reduction of colorectal cancer incidence. J Natl Cancer Inst. 2003;95:622-5.

64. Selby VJ, Friedman GD, Quesenberry Jr CP, et al. A case-control study of screening sigmoidoscopy and mortality from colorectal cancer. N Engl J Med. 1992;326:653-7.

65. Lieberman DA, Weiss DG, Bond JH, et al. Use of colonoscopy to screen asymptomatic adults for colorectal cancer. Veterans Affairs Cooperative Study Group 380. N Engl J Med. 2000;343:162-8.

66. Thiis-Evensen E, Hoff ES, Sauar J, et al. Population-based surveillance by colonoscopy: effect on the incidence of colorectal cancer. Telemark Polyp Study I. Scand J Gastroenterol. 1999;34:414-20.

67. Citairda F, Tomaselli G, Capocaccia R, The Italian Multicentre Study Group, et al. Efficacy in standard clinical practice of colonoscopic polypectomy in reducing colorectal cancer incidence. Gut. 2001;48:812-5.

68. Brenner H, Chang-Claude J, Seiler CM, et al. Does a negative screening colonoscopy ever need to be repeated? Gut. 2006;55:1145-50.

69. Muller AD, Sonnenberg A. Prevention of colorectal cancer by flexible endoscopy and polypectomy. A case-control study of 32, 702 veterans. Ann Intern Med. 1995;123:904-10.

70. Gross CP, Andersen MS, Krumholz HM, et al. Relation between Medicare screening reimbursement and stage at diagnosis for older patients with colon cancer. JAMA. 2006;296:2815-22.

71. Sedjo RL, Byers T, Barrera Jr E, et al. A midpoint assessment of the American Cancer Society challenge goal to decrease cancer incidence by $25 \%$ between 1992 and 2015. CA Cancer J Clin. 2007;57:326-40.

72. Brenner H, Haug U, Arndt V, Stegmaier C, Altenhofen L, Hoffmeister M. Low risk of colorectal cancer and advanced adenomas more than 10 years after negative colonoscopy. Gastroenterology. 2010;138(3):870-6.

73. Gatto NM, Frucht H, Sundararajan V, et al. Risk of perforation after colonoscopy and sigmoidoscopy: a population-based study. J Natl Cancer Inst. 2003;95:230-6.

74. Levin TR, Zhao W, Conell C, et al. Complications of colonoscopy in an integrated health care delivery system. Ann Intern Med. 2006;145:880-6.

75. Pabby A, Schoen RE, Weissfeld JL, et al. Analysis of colorectal cancer occurrence during surveillance colonoscopy in the dietary Polyp Prevention Trial. Gastrointest Endosc. 2005;61:38591.

76. Farrar WD, Sawhney MS, Nelson DB, et al. C olorectal cancers found after a complete colonoscopy. Clin Gastroenterol Hepatol. 2006;4:1259-64.

77. Rex DK. Maximizing detection of adenomas and cancers during colonoscopy. Am J Gastroenterol. 2006;101:2866-77.

78. Barclay RL, Vicari JJ, Doughty AS, et al. Colonoscopic withdrawal times and adenoma detection during screening colonoscopy. N Engl J Med. 2006;355:2533-41.

79. Chen SC, Rex DK. Endoscopist can be more powerful than age and male gender in predicting adenoma detection at colonoscopy. Am J Gastroenterol. 2007;102:856-61.

80. Harewood GC, Sharma VK, de Garmo P. Impact of colonoscopy preparation quality on detection of suspected colonic neoplasia. Gastrointest Endosc. 2003;58:76-9.

81. Froehlich F, Wietlisbach V, Gonvers JJ, et al. Impact of colonic cleansing on quality and diagnostic yield of colonoscopy: the European Panel of Appropriateness of Gastrointestinal Endoscopy European multicenter study. Gastrointest Endosc. 2005;61: 378-84.

82. Jain S, Johnson WD, Minocha A. Impact of quality of bowel preparation on the detection of colonic polyps during colonoscopy: a prospective study. Gastroenterology. 2007;132:A 315.

83. Cohen L, Kastenberg D, Lottes SR, et al. Polyp detection rate during colonoscopy is correlated with quality of bowel preparation. Am J Gastroenterol. 2006;101:S 556.

84. Parra-Blanco A, Nicolas-Perez D, Gimeno-Garcia A, et al. The timing of bowel preparation before colonoscopy determines the quality of cleansing, and is a significant factor contributing to the detection of flat lesions: a randomized study. World J Gastroenterol. 2006;12:6161-6.

85. Johnson CD, Chen MH, Toledano AY, et al. Accuracy of CT colonography for detection of large adenomas and cancers. $\mathrm{N}$ Engl J Med. 2008;359:1207-17.

86. Levin B, Lieberman DA, McFarland B, et al. Screening and surveillance for the early detection of colorectal cancer and adenomatous polyps, 2008: a joint guideline from the American Cancer Society, the US Multi-Society Task Force on Colorectal Cancer, and the American College of Radiology. Gastroenterology. 2008;134:1570-95.

87. Mandel JS, Bond JH, Church TR, Snover DC, Bradley GM, Schuman LM, et al. Reducing mortality from colorectal cancer by screening for fecal occult blood. Minnesota Colon Cancer Control Study. N Engl J Med. 1993;328:1365-71.

88. van Rossum LG, van Rijn AF, Laheij RJ, et al. Random comparison of guaiac and immunochemical fecal occult blood tests for colorectal cancer in a screening population. Gastroenterology. 2008;135:82-90.

89. Hol L, van Leerdam ME, van Ballegooijen $M$, et al. Attendance to screening for colorectal cancer in the Netherlands; randomized controlled trial comparing two different forms of 
faecal occult blood tests and sigmoidoscopy. Gastroenterology. 2008;134:A87.

90. Zavoral M, Suchanek S, Zavada F, Dusek L, Muzik J, Seifert B, et al. Colorectal cancer screening in Europe. World J Gastroenterol. 2009;15(47):5907-15.

91. von Wagner C, Good A, Wright D, Rachet B, Obichere A, Bloom $\mathrm{S}$, et al. Inequalities in colorectal cancer screening participation in the first round of the national screening programme in England. Br J Cancer. 2009;101 Suppl 2:S60-3.

92. Rickert RR, Auerbach O, Garfinkel L, Hammond EC, Frasca JM. Adenomatous lesions of the large bowel: an autopsy survey. Cancer. 1979;43:1847-57.

93. Williams AR, Balasooriya BA, Day DW. Polyps and cancer of the large bowel: a necropsy study in Liverpool. Gut. 1982;23:835-42.

94. Kornishi F, Morson BC. Pathology of colorectal adenomas: a colonoscopic survey. J Clin Pathol. 1982;35:830-41.

95. Fowler DL, Hedberg SE. Follow up colonoscopy after polypectomy. Gastrointest Endosc. 1980;26:A67.

96. Nugut AI, Jacobsen JS, Ahsen H, Santos J, Garbowski GC, Forde $\mathrm{KA}$, et al. Incidence and recurrence rate of colorectal adenoma: a prospective study. Gastroenterology. 1995;108:402-8.
97. Winawer SJ, Zauber AG, O'brien MJ, Nah Ho M, Gottlieb L, Sternberg SS, et al. Randomized comparison of surveillance intervals after colonoscopic removal of newly diagnosed adenomatous polyps. N Engl J Med. 1993;328:901-6.

98. Rex DX, Cutler CS, Lemmel GT, Rahmani EY, Clark DW, Helper DJ, et al. Colonoscopic miss rates of adenomas determined by back to back colonoscopies. Gastroenterology. 1997;112:24-8.

99. Noshirwani KC, van Stolk RU, Rybicki LA, Beck GJ. Adenoma size and number are predictive of adenoma recurrence: implications for surveillance colonoscopy. Gastrointest Endosc. 2000;51:433-7.

100. Atkin WS, Morson BC, Cuzick J. Long-term risk of colorectal cancer after excision of rectosigmoid adenomas. N Engl J Med. 1992;326(10):658-62.

101. Citarda F, Tomaselli G, Capocaccia R, Barcherini S, Crespi M. Efficacy in standard clinical practice of colonoscopic polypectomy in reducing colorectal cancer incidence. Gut. 2001;48:812-5.

102. Brenner H, Hoffmeister M, Arndt V, Stegmaier C, Altenhofen L, Haug U. Protection from right- and left-sided colorectal neoplasms after colonoscopy: population-based study. J Natl Cancer Inst. 2010;102(2):89-95. 